\title{
Functional capacity of natural killer cells in HTLV-1 associated myelopathy/tropical spastic paraparesis (HAM/TSP) patients
}

\author{
Gabriel Andrade Nonato Queiroz ${ }^{1,2}$, Rita Elizabeth Moreira Mascarenhas ${ }^{1,2}$, Vincent Vieillard ${ }^{3}$,
} Raphaela Lisboa Andrade ${ }^{2}$, Bernardo Galvão-Castro ${ }^{2}$ and Maria Fernanda Rios Grassi ${ }^{1,2^{*}}$

\begin{abstract}
Background: Natural killer (NK) cells are part of the innate immune system and provide surveillance against viruses and cancers. The ability of NK cells to kill virus-infected cells depends on the balance between the effects of inhibitory and activating NK cell receptors. This study aimed to investigate the phenotypic profile and the functional capacity of NK cells in the context of HTLV-1 infection.

Methods: This cross-sectional study sequentially recruited HTLV-1 infected individuals with HTLV-1 associated myelopathy/ tropical spastic paraparesis (HAM/TSP) and asymptomatic HTLV-1 (AS) from the Integrated and Multidisciplinary HTLV Center in Salvador, Brazil. Blood samples from healthy blood donors served as controls. NK cell surface receptors (NKG2D, KIR2DL2/KIR2DL3, NKp30, NKG2A, NKp46, TIM-3 and PD-1), intracellular cytolytic (Granzyme B, perforin) and functional markers (CD107a for degranulation, IFN- $\gamma$ ) were assayed by flow cytometry in the presence or absence of standard K562 target cells. In addition, cytotoxicity assays were performed in the presence or absence of anti-NKp30.

Results: The frequency of NKp30+ NK cells was significantly decreased in HAM/TSP patients [58\%, Interquartile Range (IQR) 30-61] compared to controls (73\%, IQR 54-79, $p=0.04$ ). The production of cytolytic (perforin, granzyme B) and functional markers (CD107a and IFN- $\gamma$ ) was higher in unstimulated NK cells from HAM/TSP and AS patients compared to controls. By contrast, stimulation with K562 target cells did not alter the frequency of CD $107 a^{+}$NK cells in HAM/TSP subjects compared to the other groups. Blockage of the NKp30 receptor was shown to decrease cytotoxic activity (CD107a) and IFN- $\gamma$ expression only in asymptomatic HTLV-1-infected individuals.
\end{abstract}

Conclusions: NK cells from individuals with a diagnosis of HAM/TSP present decreased expression of the activating receptor NKp30, in addition to elevated degranulation activity that remained unaffected after blocking the NKp30 receptor.

Keywords: NK cells, NKp30, Natural cytotoxicity receptor, CD107, HTLV-1, HAM/TSP

\section{Background}

Human T-lymphotropic virus type 1 (HTLV-1) has been associated with adult T-cell leukemia/Lymphoma (ATLL) [1], infective dermatitis [2] and other inflammatory diseases [3]. This virus may also lead to HTLV-1 associated myelopathy/tropical spastic paraparesis (HAM/TSP), a progressive inflammatory demyelinating disease affecting

\footnotetext{
* Correspondence: fernanda.grassi@fiocruz.br

'Laboratório Avançado de Saúde Pública, Instituto Gonçalo Muniz, Fundação Oswaldo Cruz - Fiocruz, Salvador, Bahia, Brazil

Escola Bahiana de Medicina e Saúde Pública, Salvador, Bahia, Brazil Full list of author information is available at the end of the article
}

the spinal cord [4]. Patients with HAM/TSP present an infiltrate of infected T-lymphocytes and cytotoxic T-lymp hocytes (CTL) specific for viral antigens in their cerebrospinal fluid, in addition to increased proinflammatory cytokine (IFN- $\gamma$, TNF- $\alpha$ ) and chemokine (CXCL-9 and CXCL-10) production [5, 6].

High proviral loads have been associated with the development of HAM/TSP [7, 8], as well as with the development of infective dermatitis [9], Keratoconjunctivitis sicca [10] and bronchiectasis [3]. Moreover, increased proviral loads and an exacerbated activation of the immune system may also be seen in asymptomatic individuals infected with HTLV-1 $[11,12]$. 
Proviral load can become suppressed or be maintained at stable levels due to the intense and specific activity of cytotoxic $\mathrm{CD}^{+}{ }^{+}$T-lymphocytes (CTL) against HTLV-1-infected cells $[13,14]$. In contrast to CTLs, NK cells are understood to provide surveillance in the defense against viruses and tumor cells, without the need for prior sensitization. NK cell activity is regulated by a dynamic balance of signaling among a vast network of activating and inhibitory receptors, which become triggered upon interaction with their cognate ligands to detect cellular targets while sparing normal cells. Under typical physiological circumstances, NK cells express inhibitory receptors that recognize selfmolecules of the HLA-I repertoire, which are constitutively expressed on the surfaces of host cells. In order for NK cells to mount an efficient response, a critical signaling threshold must be reached in which activating receptors exceed the counterbalancing influence of inhibitory receptors [15]. Lower frequencies of circulating NK cells have been reported in patients with HAM/TSP compared to asymptomatic carriers [16-18]. Nonetheless, the role of the NK cellular response in HTLV-1 infection requires further clarification. Accordingly, the present study aimed to investigate the phenotypic profile of NK cells and to evaluate their functional capacity in the context of HTLV-1 infection, especially in subjects with HAM/TSP.

\section{Methods}

\section{Ethical considerations}

The present research protocol was approved by the Institutional Research Board (IRB) of the Bahiana School of Medicine and Public Health (EBMSP) in Salvador, BahiaBrazil (protocol no. 187/2011). All procedures were performed in accordance with the principles established in the Declaration of Helsinki and its subsequent revisions.

\section{Patients}

For this cross-sectional study, HTLV-1-infected individuals were selected by convenience sampling at the Integrated and Multidisciplinary HTLV Center, (Salvador, Bahia-Brazil). All participants were sequentially included at the time of their previously scheduled appointments. Inclusion criteria were individuals of both genders, 18 to 65 years of age, with an available neurological evaluation used to differentiate asymptomatic from HAM/TSP individuals. Myelopathic symptoms, serological findings, and/ or the detection of HTLV-1 DNA, as well as the exclusion of other disorders were all used as indicators in the diagnosis of HAM/TSP [19]. Asymptomatic individuals (AS) were included if their neurological examinations were normal and they reported no clinical complaints. Eighteen laboratory staff and/or healthy blood donors were included as non-infected controls. Any individuals with HIV, HBV and/or HCV were excluded. HTLV-1 infection was diagnosed using ELISA (Cambridge Biotech Corp., Worcester,
MA) and confirmed by Western Blot analysis (HTLV blot 2.4, Genelab, Singapore).

\section{Cells}

Peripheral blood mononuclear cells (PBMC) from HTLV1-infected individuals and non-infected controls were obtained by Ficoll-Hypaque density gradient centrifugation (Sigma Chemical Co., St. Louis, MO) and stored in liquid nitrogen until use. After thawing, any samples presenting less than $85 \%$ viability were discarded.

\section{Immunophenotyping by flow cytometry}

PBMCs were incubated for $20 \mathrm{~min}$ at room temperature with the following combinations of fluorescence-conjugated monoclonal antibodies (MAbs): (FITC)-labeled fluorescein isothiocyanate, anti-NKG2D, anti-KIR2DL2/KIR2DL3 and anti-TIM-3; phycoerythrin (PE)-labeled anti-NKP30, anti-NKG2A and anti-PD-1; Allophycocyanin-cyanin-7 (APCCY7) anti-CD3; Brilliant violet 421 (BV421)-labeled anti-CD56; Brilliant violet 510 (BV510) anti-NKP46. The following isotype controls were used: (APCCY7-IgG2a); (PECY7-IgG1); (BV421-IgG1); (PE-IgG1-extracellular); (PE-IgG1-intracellular); (FITC-IgG1); (BV510-IgG1); (AF647-IgG1). All MAbs were purchased with the (Biolegend, San Diego, CA, EUA), except anti-NKG2A (Miltenyi Biotec, Bergisch Gladbach, Germany). All cells were then washed and fixed in PBS containing 1\% formaldehyde (Sigma-Aldrich) for $20 \mathrm{~min}$. Cells were acquired using flow cytometry (BD Facs RSFortessa $^{\mathrm{Tm}}$, San Jose, CA, EUA) and analyzed by Software FlowJo (Tree Star), with at least 50,000 events considered. Representative flow cytometry dot plots are shown in Fig. 1 (A-I).

\section{NK cell degranulation assays and intracellular cytokine production}

Polyfunctional assays simultaneously detected NK cell degranulation (evidenced by CD107a surface expression) and the intracellular production of IFNy. $106 \mathrm{PBMC} / \mathrm{ml}$ were incubated in RPMI 1640 (Sigma) containing 10\% FCS (Gibco, Waltham, MA, USA), 2 mM L-glutamine, 1\% nonessential amino acids, $1 \mathrm{mM}$ sodium pyruvate, $100 \mathrm{U} / \mathrm{ml}$ penicillin and $100 \mathrm{~g} / \mathrm{ml}$ streptomycin (Sigma) in the presence of an anti-CD107a-FITC antibody (Biolegend, San Diego, CA, EUA) for $6 \mathrm{~h}$ at $37^{\circ} \mathrm{C}$ under $5 \% \mathrm{CO} 2$. After the first hour of culturing, brefeldin $\mathrm{A}$ and monensin were added $(2 \mu \mathrm{g} / \mathrm{ml})$ (Sigma). Similar assays were performed in the presence of $\mathrm{K} 562$ target cells (ATCC CCL-243) at an effector to target ratio of 1:1 in the presence or absence of $4 \mu \mathrm{g} / \mathrm{ml}$ of anti-NKp30 (Biolegend- San Diego, CA, USA). All cells were then washed and stained with CD3APC-CY7, CD8-PE-CY7 and CD56-BV421 antibodies (Biolegend - San Diego, CA, USA) for $20 \mathrm{~min}$. After washing, cells were fixed in 1\% PBS/formaldehyde for $20 \mathrm{~min}$, followed by two washing cycles with $0.1 \%$ PBS-BSA/ 


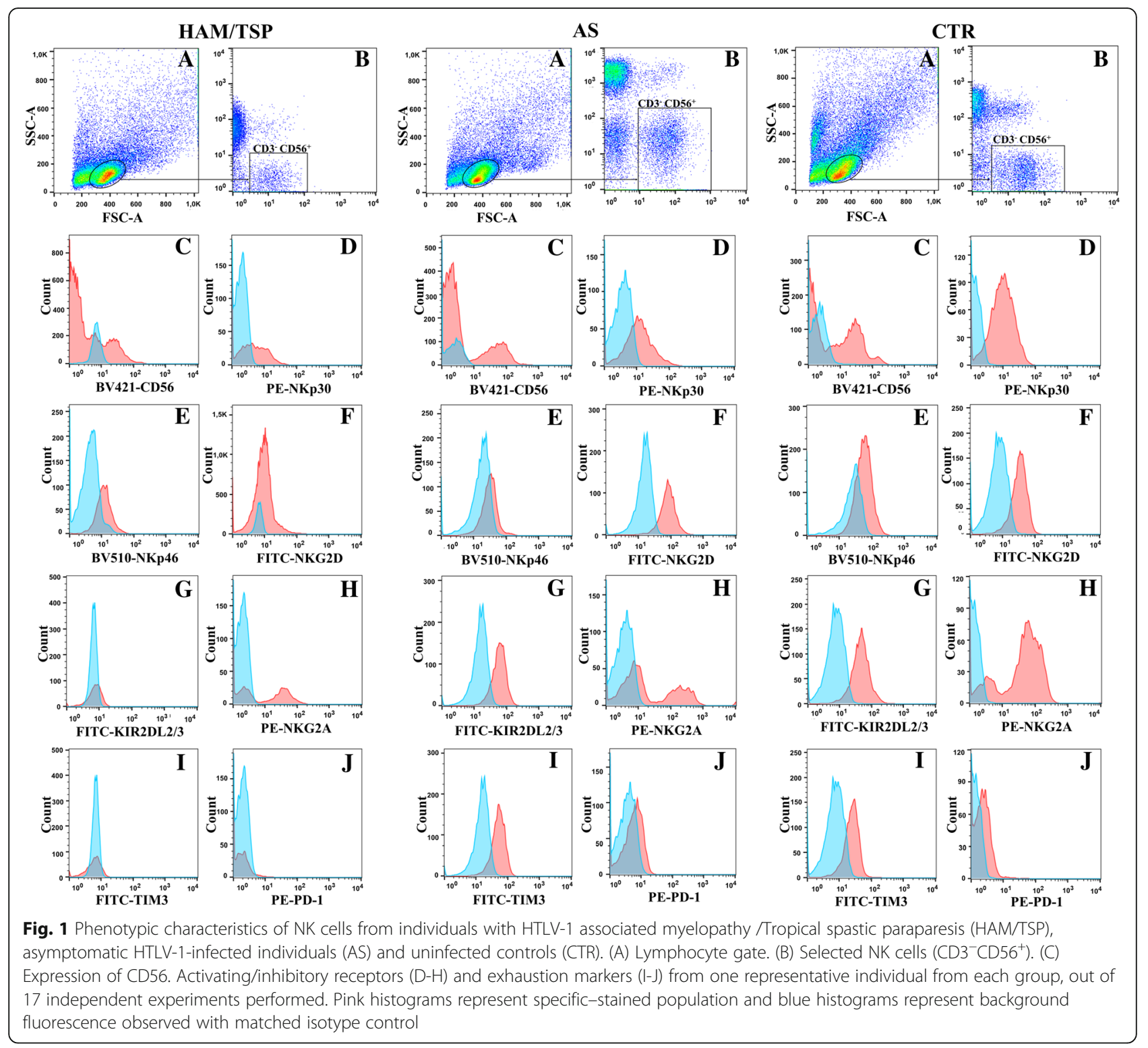

Saponin. The cells were then incubated with anti-granzyme B-Alexa-Fluor 647 (Becton Dickinson Pharmingen, San Jose, CA, EUA), anti-perforin-PE and anti-IFN- $\gamma$-PE (Biolegend, San Diego, CA, EUA) for $30 \mathrm{~min}$. Finally, the stained cells were acquired using flow cytometry (BD Facs RSFortessa $^{\text {Ts }}$, San Jose, CA, EUA) and analyzed by Software FlowJo (Tree Star) considering at least 50,000 events.

\section{Proviral load}

DNA was extracted from PBMCs using a spin column DNA extraction system (Qiagen, Hilden, Germany). HTLV-1 proviral load was quantified using a previously described real-time TaqMan polymerase chain reaction (PCR) method [20]. HTLV-1 proviral load was calculated as [(average number of HTLV-1 copies)/(average number of albumin copies)] $\times 2 \times 10^{6}$, and is expressed as the number of HTLV-1 copies per $10^{6}$ PBMCs.

\section{Statistical analysis}

Age is expressed as mean with standard deviation, while other data are expressed as median and interquartile range (25th and 75th percentiles). Comparisons of proviral load between the AS and HAM/TSP groups were performed using the Mann-Whitney U-test. The Kruskal-Wallis analysis of variance and Bonferroni-Dunn multiple comparison tests were used to compare among healthy donors, AS and HAM/TSP groups. Chi-square test was used to compare sex frequencies. Wilcoxon's test was used to compare the cytotoxic activity of NK cells in the presence or absence of the anti-NKp30 monoclonal antibody. Correlations were performed using Spearman's correlation test. Differences 
were considered significant when $p<0.05$. GraphPad Prism v5 (La Jolla, CA) software was used for all statistical analyses.

\section{Results}

\section{Clinical characteristics}

A total of 20 individuals with a diagnosis of HAM/TSP, 28 asymptomatic carriers and 18 uninfected healthy controls were included. The mean ages of the HAM/TSP (48.7 \pm 10), AS (42.9 \pm 11.4$)$ and uninfected control (CTR) (41.4 \pm 14.2 ) groups were similar. The median HTLV-1 proviral load in the HAM/TSP group was significantly higher than the AS group $\left(173,146 \mathrm{vs} .10,101 \mathrm{copies} / 10^{6} \mathrm{PBMCs}\right.$, respectively) $(p=0.0001)$. Spasticity in the lower limbs was present in all HAM/TSP individuals, yet absent in AS and controls. Overactive bladder was detected only in $76 \%$ of HAM/TSP individuals (Table 1 ).

Phenotypic profile of inhibitory, activating and exhaustion markers in NK cells.

The median frequency $\mathrm{CD}^{-} \mathrm{CD}^{-} 6^{+} \mathrm{NK}$ cells was similar in HAM/TSP patients ( $3 \%$, IQR 1-6), AS carriers ( $2 \%$, IQR 1-3) and CTR (5\%, IQR 2-8). In order to better characterize NK cells, cell-surface receptors were extensively analyzed. The frequency of $\mathrm{CD}^{+} 6^{+} \mathrm{NK}$ cells in HTLV-1-infected individuals was statistically matched to that of the CTR in terms of inhibitory KIR2DL2/KIR2DL3 and NKG2A receptors, NKG2D and NKp46 activating receptors, as well as markers of cell exhaustion (TIM-3 and PD-1) (Fig. 1 and Fig. 2b-h). In contrast, the frequency of NKp30+ NK cells in individuals with HAM/ TSP (58\%, [30-61]) was lower compared to CTR (73\%, [54-79], $(p=0.04)$ (Fig. 2a).

\section{Cytotoxic marker and IFN- $\gamma$ expression by NK cells}

To determine the functional significance of the present phenotypic findings, we investigated the intracellular expression of IFN- $\gamma$ by NK cells, as well as the cytotoxic markers perforin, granzyme B and CD107a. While no differences were seen in IFN- $\gamma$ expression in the absence of stimulation with K562 target cells, this functional marker was found to be significantly upregulated in both HAM/ TSP $(p=0.03)$ and AS $(p=0.03)$ individuals groups compared to CTR (Fig. 3a) following stimulation. The percentage of unstimulated NK cells expressing perforin (Fig. 3b) and granzyme B (Fig. 3c) was significantly higher among HTLV-1-infected individuals (HAM/TSP and AS) compared to CTR ( $p=0.003$ and $p=0.04$, respectively). In response to stimulation with $\mathrm{K} 562$ target cells, perforin expression was found to be increased only in CTR NK cells, while granzyme B expression was higher in NK cells from the AS and CTR groups. The evaluation of the degranulation capacity of NK cells revealed elevated levels of CD107a in HLTV-1-infected individuals compared to CTR in the absence of stimulation by target cells, and even higher levels in HAM/TSP $(p=0.03)$ than in AS (Fig. 3d). Moreover, the frequency of $\mathrm{CD} 107 \mathrm{a}^{+} \mathrm{NK}$ cells was higher in AS and CTR groups following stimulation by $\mathrm{K} 562$ target cells, yet no significant changes were observed in the frequency of these cells in the HAM/TSP group regardless of stimulation. Representative flow plots showing relative NK cell expression of CD107a, perforin, granzyme B and IFN $-\gamma$ are shown in Fig. 4.

\section{Effect of Nkp30 receptor blockage on cytotoxic marker and IFN- $\gamma$ expression by NK cells}

To evaluate the relationship of NKp30 inhibition with respect to cytotoxicity, an assay using the anti-NKp30 monoclonal antibody was performed in an attempt to block its receptor (Fig. 5). While blockage of the NKp30 receptor did not alter cytotoxic activity (CD107a) or IFN- $\gamma$ expression in the HAM/TSP group, cytotoxicity decreased by $48 \%(P=0.01)$ and IFN- $\gamma$ expression fell by $42 \%(P=0.01)$ in the AS group. Similar results were also observed with respect to the degranulation markers analyzed after $18 \mathrm{~h}$ of culturing (data not shown). Of note, no correlations were found between HTLV-1 proviral load and any of the phenotypic or functional NK-cell markers investigated herein.

\section{Discussion}

Few reports have described decreased cytotoxic activity in NK cells in HTLV-1 infection [18, 21], and none have attempted to evaluate cytotoxic function through the use of degranulation markers. The present study provides novel insight into the involvement of NK cells in the pathophysiology of HTLV-1. Specifically, we observed a decrease in the frequency of NK cells expressing the activating receptor

Table 1 Clinical and demographic characteristics of all individuals included in the study

\begin{tabular}{|c|c|c|c|c|c|c|}
\hline \multirow[t]{2}{*}{ Groups } & \multirow{2}{*}{$\begin{array}{l}\text { Age (Years) } \\
\text { Mean } \pm S D\end{array}$} & \multicolumn{2}{|c|}{ Gender - n (\%) } & \multirow{2}{*}{$\begin{array}{l}\text { PVL } \\
\text { Median (IQR 25-75) }\end{array}$} & \multirow{2}{*}{$\begin{array}{l}\text { Spasticity in lower limbs } \\
n(\%)\end{array}$} & \multirow{2}{*}{$\begin{array}{l}\text { Overactive bladder } \\
n(\%)\end{array}$} \\
\hline & & $\mathrm{F}$ & M & & & \\
\hline $\mathrm{HAM} / \mathrm{TSP}(n=20)$ & $48.7 \pm 10$ & $13(65.0)$ & $7(35.0)$ & $173,146(94,232-240,393)^{*}$ & 20 (100) & $13(76)^{a}$ \\
\hline $\operatorname{AS}(n=28)$ & $42.9 \pm 11.4$ & $19(67.9)$ & $9(32.1)$ & $10,101(1659-36,326)$ & 0 & 0 \\
\hline $\operatorname{CTR}(n=18)$ & $41.4 \pm 14.2$ & $10(55.6)$ & $8(44.4)$ & - & 0 & 0 \\
\hline
\end{tabular}

HAM/TSP HTLV-1-associated myelopathy/Tropical spastic paraparesis, AS Asymptomatic, CTR Uninfected controls, $n$ Number, SD Standard Deviation, $F$ Female, $M$ Male, IQR Interquartile range, PVL HTLV-1 Proviral load (copies $/ 10^{6} \mathrm{PBMC}$ ), performed for 14 patients with HAM/TSP and 24 asymtomatic individuals. a Data available from only $17 \mathrm{HAM} / \mathrm{TSP}$ patients. Statistical analysis of differences between groups determined by the Kruskal-Wallis test, followed by Dunn's post-test. Statistical analysis of proviral load performed using the Mann-Whitney test. * $(p=0.0001)$ 


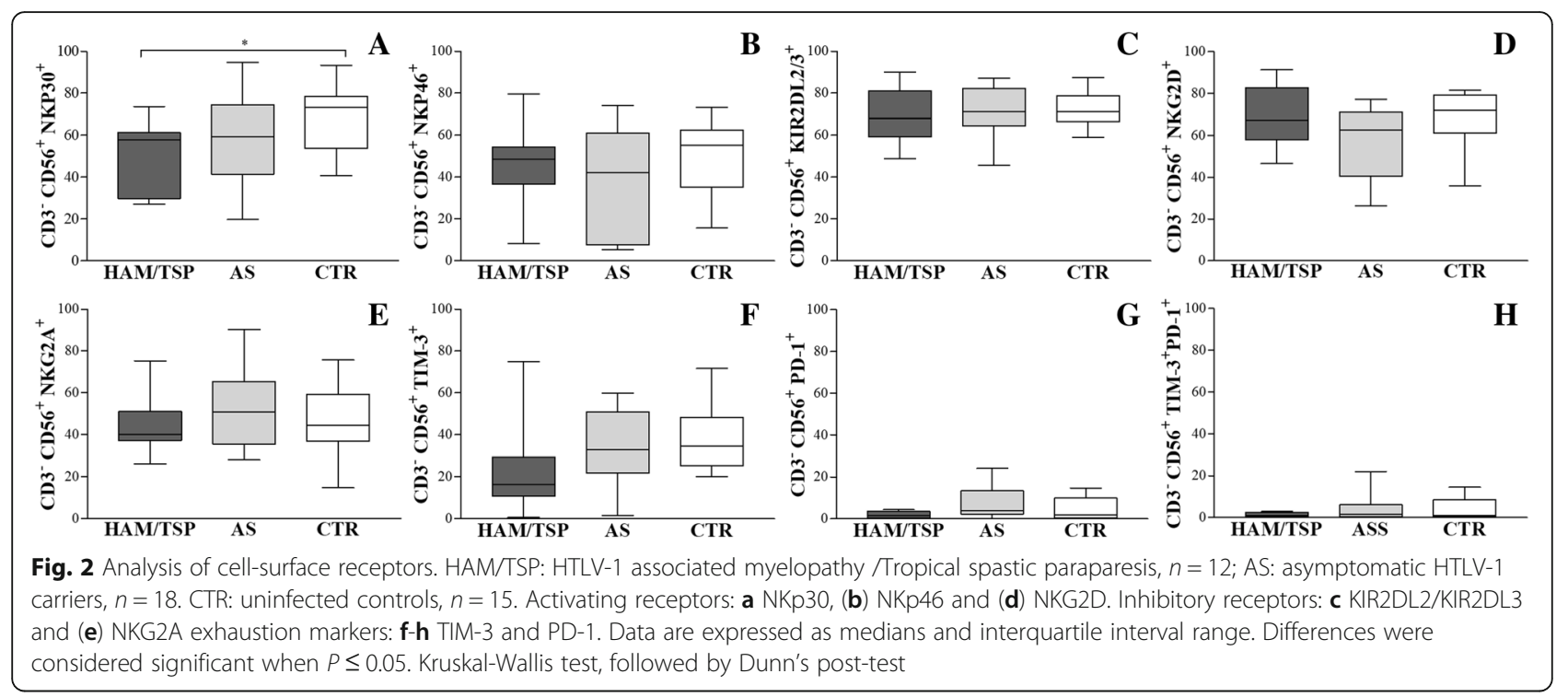

NKp30 in individuals with a diagnosis of HAM/TSP compared to uninfected controls, as well as high degranulation activity in the absence of stimuli, as reflected by increased cytolytic (granzyme B and perforin) and degranulation marker expression. Moreover, NK cells from HAM/TSP individuals exhibited no increases in NK cells expressing degranulation markers (CD107a) or granzyme B following stimulation with $\mathrm{K} 562$ cells, as compared to AS and CTR groups. Additionally, blockage of the activating receptor NKp30 had no effect on the cytotoxic activity of NK-cells or IFN- $\gamma$ expression in HAM/TSP individuals, in contrast to the decreased expression of these markers seen in asymptomatic carriers. These results indicate that NK cells from HTLV-1-infected individuals are in a state of continuous activation, especially the hypo-responsive NK cells found in HAM/TSP

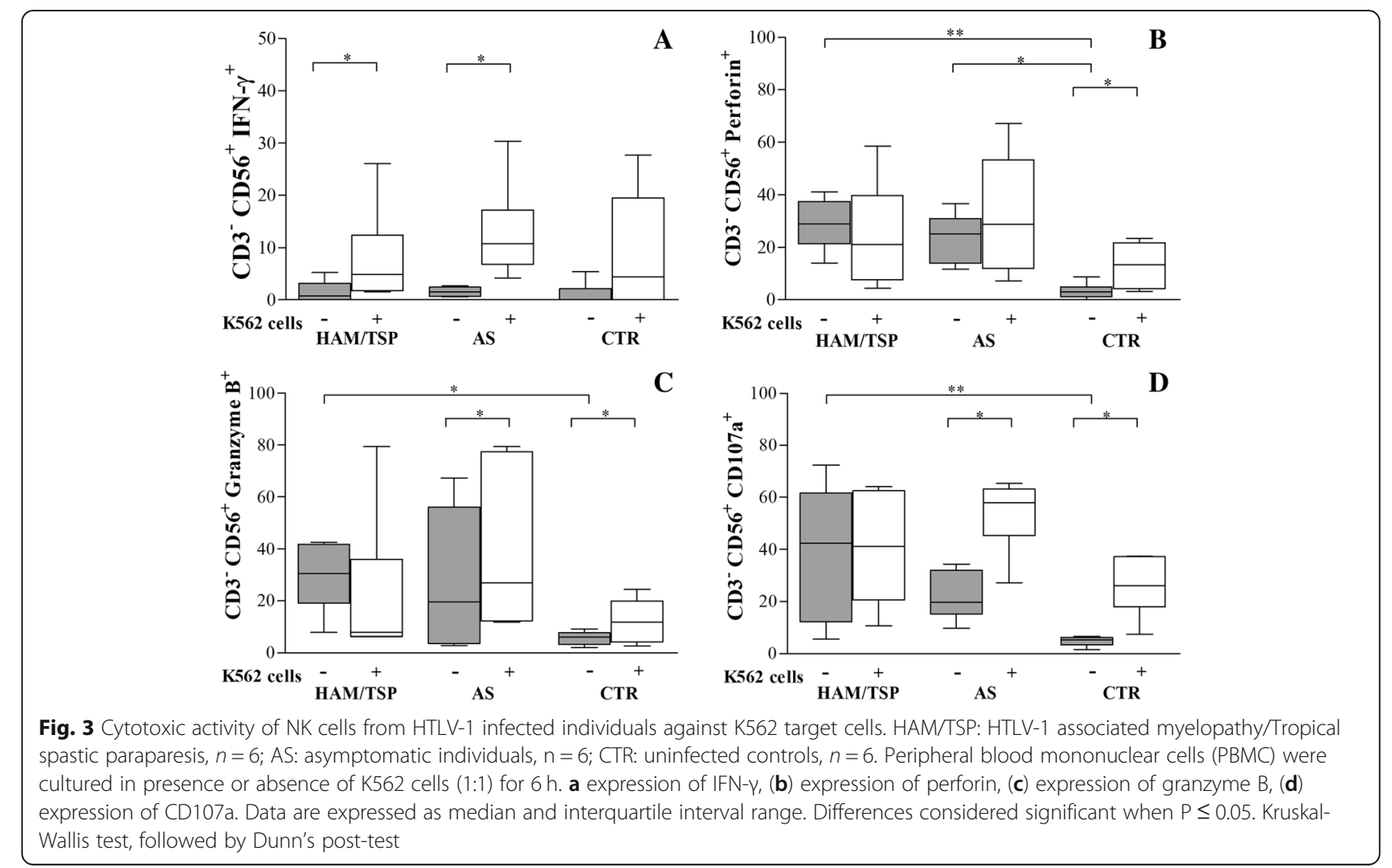




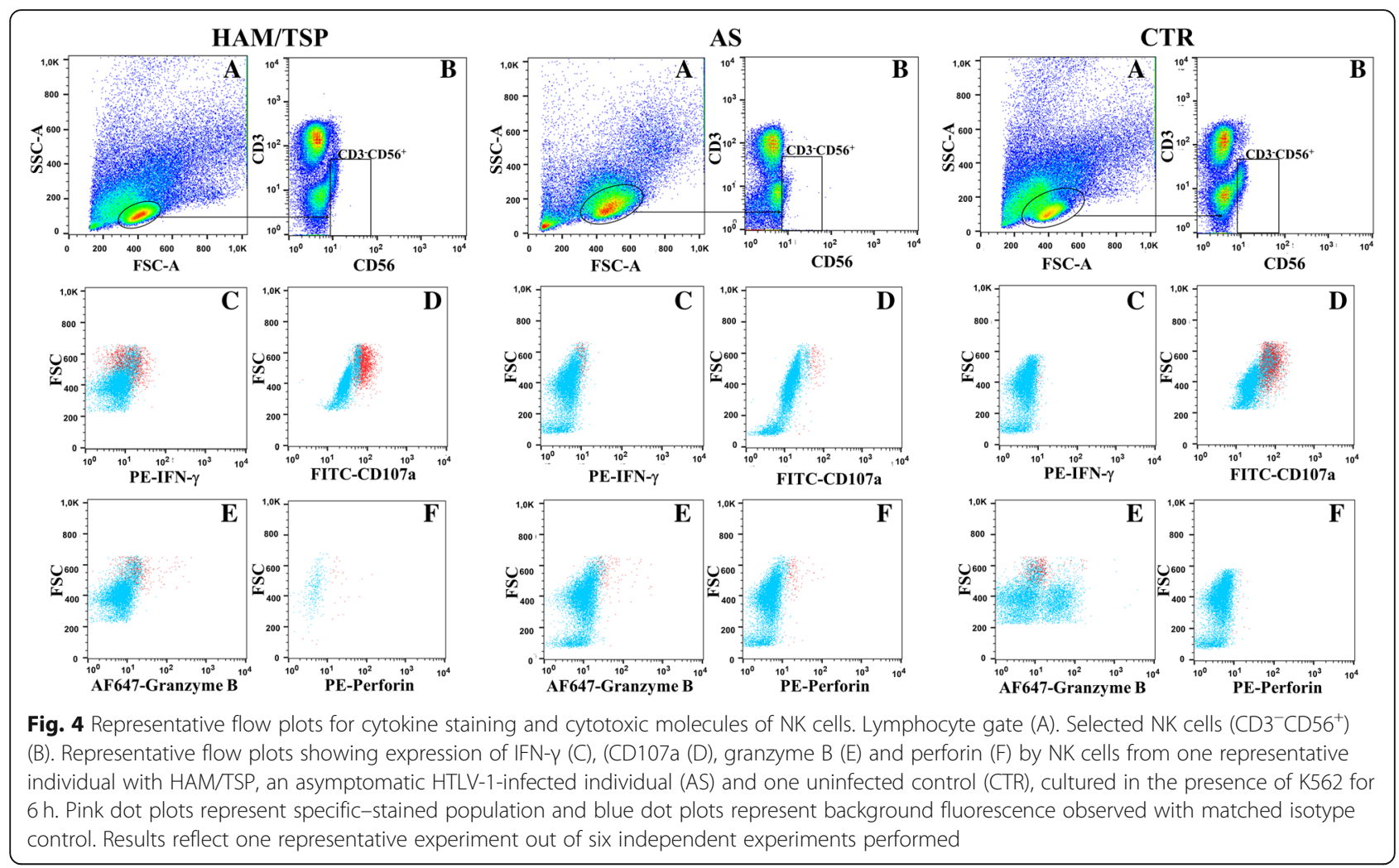

individuals. HTLV-1 infection is known to induce a potent activation of the immune system in both HAM/TSP and asymptomatic individuals [11, 12]. The spontaneous proliferation of T-cells and NK cells, increased expression of the activation markers HLA$\mathrm{DR}, \mathrm{CD} 25$ and $\mathrm{CD} 45 \mathrm{RO}^{+}$, and increased proinflammatory cytokine production are all found to a greater extent in HTLV-1-infected individuals compared to uninfected controls [11, 12, 22, 23].
Additionally, the expression of TIM-3 and PD-1 was similar among groups, suggesting that exhaustion was not implicated in the hypo-responsiveness observed in NK cells from HAM/TSP individuals. However, it is possible that other persistent viral infections might induce cellular exhaustion, thereby leading to an impairment in effector function [24]. Indeed, SIV-infected non-human primate NK cells showed increased TIM-3 expression and failed to lyse target cells [25]. In addition, increased
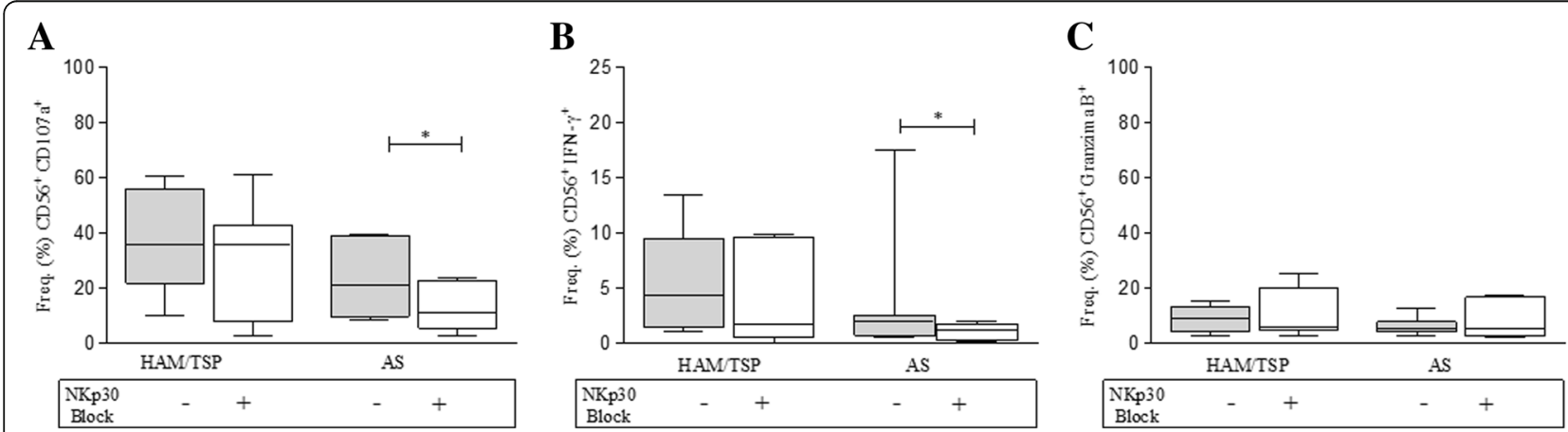

Fig. 5 Cytotoxic activity of NK cells from HTLV-1 infected individuals against K562 target in the presence or absence of anti-NKp30 monoclonal antibody. Peripheral blood mononuclear cells (PBMC) were cultured in the presence of K562 cells (1:1), and in the presence or absence of NKp30

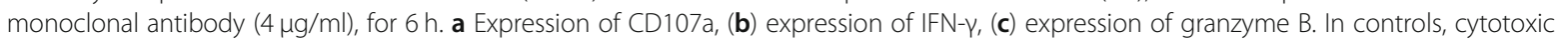
activity (CD107a) was reduced by $36 \%$ in the presence of anti-NKp30 antibody. Data are expressed as medians and interquartile interval range. HTLV-1 associated myelopathy/Tropical spastic paraparesis (HAM/TSP), $n=6$; AS: asymptomatic individuals, $n=6$. Differences were considered significant when $P \leq 0.05$, Wilcoxon-test. ${ }^{*} p=0.01$ 
TIM-3 and PD-1 were also described in NK cells from individuals with hepatitis and cytomegalovirus [26].

In this study, we observed that levels of NKp30 decreased significantly in HAM/TSP patients. The activating NKp30 receptor has also been associated with increased NK cell efficiency in the lysing of tumor cells. In the context of other chronic viral infections, lower NKp30 expression was found in HPV-associated cervical cancer [27], AIDS [28] and $\mathrm{HCV}$-infected individuals with cirrhosis [29]. In HIV-infected individuals, reduced NKp30 expression was observed in $\mathrm{CD} 56^{\mathrm{dim}}$ and $\mathrm{CD} 56^{\text {neg }}$ NK cell subsets, although this was not determined to be of prognostic value [30]. Similarly, in acute viral infection, such as dengue virus type 2 , NK cells expressed significantly lower levels of NKp30 compared to healthy individuals [31]. Accordingly, reductions in NKp30 may be indicative of alterations in innate immune response, as reflected by its occurrence in the context of severe manifestations of chronic viral infection, e.g. individuals with HAM/TSP.

Distinct isoforms of NKp30 may impact NK function. To date, three splice variants of NKp30 have been identified: NKp30C, an immunosuppressive isoform, as well as the activating isoforms $\mathrm{NKp} 30 \mathrm{~A}$ and $\mathrm{B}$, which have been reported to affect NK cell function and may be correlated with the clinical outcome of gastrointestinal tumors (GIST). Low NKp30B/C ratios have been observed in response to higher transcription levels of isoform $C$, while a low NKp30A/C ratio was attributed to diminished isoform B expression; both of these findings suggest that differing ratios of the NKp30 isoforms may influence the outcome of GIST [32]. Furthermore, surface molecules BAT-3 and B7-H6 have been described as NKp30 cellular ligands. Despite the fact that Semeraro and colleges presented evidence regarding the clinical impact of $\mathrm{NKp} 30$ and its ligand $\mathrm{B} 7-\mathrm{H} 6$ [33] in patients with high risk neuroblastoma [34], no studies have clarified this association in the outcome of viral infections.

It has been previously suggested that the sensitivity of HTLV-1-positive cell lines to NK-mediated cell lysis was inversely correlated with tumorigenicity in an SCID model [35], implying that NK cells may prevent tumor induction and/or development in vivo. The efficiency of NK cells as a defense mechanism remains a topic of debate in chronic infections, such as HTLV-1. Hanon et al. (2000) did not observe significant reductions in $\mathrm{CD} 4^{+} \mathrm{T}$-cells infected by HTLV-1 in NK-depleted cell cultures as compared to CD8 ${ }^{+}$ T-lymphocytes, suggesting that NK cells may play a limited role in the control of HTLV-1 infection [13]. These conflicting results might also be reflective of major inconsistencies among experimental models. Regardless, further study is required to determine whether NK cells represent an efficient defense mechanism, especially in the context of HTLV-1.

The present study found high rates of spontaneous degranulation, which resulted in the elevated production of granzyme B and perforin, as well as IFN- $\gamma$ expression, in NK cells from HTLV-1-infected individuals. Unexpectedly, NK cells from HAM/TSP subjects became hypo-functional in response to stimulation with K562 target cells, in spite of the elevated IFN- $\gamma$ production typically seen in HTLV-1 infection [36, 37]. Reduced cytotoxic activity in HAM/TSP individuals was previously associated with a lower frequency of NK cells expressing $\mathrm{CD}^{+} 6^{+}$and $\mathrm{CD}_{11 \mathrm{~b}^{+}}[18,21,38]$, which might indicate the possible role of antibodydependent cellular cytotoxicity mediated by NK cells.

A clear association between HAM/TSP diagnosis and high HTLV-1 proviral load has been observed in several studies conducted in Japan, Martinique, Brazil, United Kingdom and Iran [7, 8, 39-41]. Herein HTLV-1 proviral load was also consistently higher in HAM/TSP patients compared with AS individuals, however no correlations were found between HTLV-1 proviral load and any of the markers evaluated. The absence of correlations could be due to the relatively small number of individuals evaluated. However, while our data do not provide evidence that proviral load is associated with another NK marker (not tested in this study), we can highlight that NKp30 expression was, for the first time, found to discriminate asymptomatic individuals from HAM/TSP patients.

A limitation of the present study was that the NK cells evaluated were derived from total PBMCs instead of taking into account a purified population. However, as this subset constitutes a very small portion of PBMCs, the purification of these cells would require much larger amounts of blood to be drawn from patients, which was infeasible. Another important limitation was that no correlation could be established between the clinical outcomes of HTLV-1-infected patients and NK cell marker expression, which was likely a result of the limited number of studied individuals and the highly variable expression seen in the markers evaluated.

\section{Conclusions}

In summary, unstimulated NK cells from HAM/TSP patients presented decreased expression of the NKp30 receptor and higher levels of cytolytic markers in comparison to asymptomatic individuals and uninfected controls. Moreover, NK cells from HAM/TSP individuals were found to be hypo-responsive following stimulation with target cells or blockage of the NKp30 receptor. These findings seem to suggest that decreases in the expression of NKp30 could influence the functional capacity of NK cells in subjects with HAM/TSP. Further studies should be conducted to comprehensively evaluate the role of interactions between activating/ inhibiting receptors and their ligands with respect to cytotoxic response. 


\section{Abbreviations}

AS: Asymptomatic HTLV-1; ATLL: Adult T-cell leukemia/lymphoma; CHTLV: Integrative and Multidisciplinary Center for HTLV (a center that provides care for patients infected with the virus); HAM/TSP: HTLV-1 Associated Myelopathy / Tropical Spastic Paraparesis; HTLV-1: Human Tlymphotropic virus type 1; NK: Natural killer

\section{Acknowledgments}

We thank Dr. Raymond Césarie for providing HTLV/Albumina clones, Dr. Viviana Olavarria, and Noilson Lazaro for technical assistance, and Andris K. Walter for English revision and copyediting services.

\section{Funding}

This work was supported by the Fundação de Amparo a Pesquisa da Bahia (FAPESB) and by the Coordenação de Aperfeiçoamento de Pessoal de Nível Superior - Brasil (CAPES) - Finance Code 001. Grassi, M.F.R. and Galvão-Castro, $B$, are currently receiving scholarships from Conselho Nacional de Desenvolvimento Científico e Tecnológico (CNPq) and from Fundação Nacional de Desenvolvimento do Ensino Superior Particular (Funadesp). The funding agencies had no role in the design of the study, data collection, analysis, interpretation of data nor in the writing the manuscript.

\section{Availability of data and materials}

The datasets used and/or analyzed in the current study are available from the corresponding author upon reasonable request.

\section{Authors' contributions}

All authors have read and approved the final version of the manuscript. REMM, BGC, W and MFRG designed research; GANQ and RLA performed experiments; REMM, BGC, MFRG and W contributed new reagents/analytic tools; REMM, GANQ, RLA, BGC, MFRG and W analyzed data; and GANQ, REMM, W and MFRG wrote the paper.

\section{Ethics approval and consent to participate}

The Institutional Research Board of the Bahiana School of Medicine and Public Health (187/2011) granted approval of this study. Written informed consent was obtained from all enrolled patients.

\section{Consent for publication}

Not applicable.

\section{Competing interests}

The authors declare that they have no competing interests.

\section{Publisher's Note}

Springer Nature remains neutral with regard to jurisdictional claims in published maps and institutional affiliations.

\section{Author details}

'Laboratório Avançado de Saúde Pública, Instituto Gonçalo Muniz, Fundação

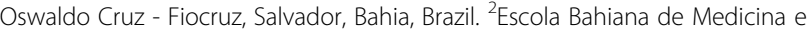
Saúde Pública, Salvador, Bahia, Brazil. ${ }^{3}$ Centre d'Immunologie et des Maladies Infectieuses (CIMI-Paris), Sorbonne Universités, UPMC Univ Paris 06, INSERM U1135, CNRS ERL8255, Paris, France.

\section{Received: 29 June 2018 Accepted: 26 April 2019}

\section{Published online: 17 May 2019}

\section{References}

1. Hinuma Y, Nagata K, Hanaoka M, Nakai M, Matsumoto T, Kinoshita Kl, et al. Adult T-cell leukemia: antigen in an ATL cell line and detection of antibodies to the antigen in human sera. Proc Natl Acad Sci. 1981;78(10):6476-80.

2. LaGrenade L, Hanchard B, Fletcher V, Cranston B, Blattner W. Infective dermatitis of Jamaican children: a marker for HTLV-I infection. Lancet. 1990; 336(8727):1345-7.

3. Honarbakhsh S, Taylor GP. High prevalence of bronchiectasis is linked to HTLV-1-associated inflammatory disease. BMC Infect Dis. 2015;15:258 Epub 2015/07/06.

4. Gessain A, Vernant J, Maurs L, Barin F, Gout O. Calender ad. Antibodies to human T-lymphotropic virus type-l in patients with tropical spastic paraparesis. Lancet. 1985;326(8452):407-10.
5. Guerreiro J, Santos S, Morgan D, Porto A, Muniz A, Ho J, et al. Levels of serum chemokines discriminate clinical myelopathy associated with human T lymphotropic virus type 1 (HTLV-1)/tropical spastic paraparesis (HAM/TSP) disease from HTLV-1 carrier state. Clin Exp Immunol. 2006;145(2):296-301.

6. Sato T, Coler-Reilly A, Utsunomiya A, Araya N, Yagishita N, Ando H, et al. CSF CXCL10, CXCL9, and neopterin as candidate prognostic biomarkers for HTLV-1-associated myelopathy/tropical spastic paraparesis. PLoS Negl Trop Dis. 2013;7(10):e2479 Epub 2013/10/17.

7. Olindo S, Lezin A, Cabre P, Merle H, Saint-Vil M, Edimonana Kaptue M, et al. HTLV-1 proviral load in peripheral blood mononuclear cells quantified in 100 HAM/TSP patients: a marker of disease progression. J Neurol Sci. 2005; 237(1-2):53-9.

8. Grassi MF, Olavarria VN, Kruschewsky Rde A, Mascarenhas RE, Dourado I, Correia LC, et al. Human T cell lymphotropic virus type 1 (HTLV-1) proviral load of HTLVassociated myelopathy/tropical spastic paraparesis (HAM/TSP) patients according to new diagnostic criteria of HAM/TSP. J Med Virol. 2011;83(7):1269-74.

9. Primo J, Siqueira I, Nascimento MC, Oliveira MF, Farre L, Carvalho EM, et al. High HTLV-1 proviral load, a marker for HTLV-1 associated myelopathy/ tropical spastic paraparesis, is also detected in patients with infective dermatitis associated with HTLV-1. Braz J Med Biol Res. 2009;42(8):761-4 Epub 2009/07/07.

10. Castro-Lima Vargens C, Grassi MF, Boa-Sorte N, Rathsam-Pinheiro RH, Olavarria VN, de Almeida Kruschewsky R, et al. Keratoconjunctivitis sicca of human T cell lymphotropic virus type 1 (HTLV-1) infected individuals is associated with high levels of HTLV-1 proviral load. J Clin Virol. 2011;52(3):177-80.

11. Santos SB, Porto AF, Muniz AL, de Jesus AR, Magalhaes E, Melo A, et al. Exacerbated inflammatory cellular immune response characteristics of HAM/ TSP is observed in a large proportion of HTLV-I asymptomatic carriers. BMC Infect Dis. 2004;4:7.

12. Coutinho R Jr, Grassi MF, Korngold AB, Olavarria VN, Galvao-Castro B, Mascarenhas RE. Human T lymphotropic virus type 1 (HTLV-1) proviral load induces activation of T-lymphocytes in asymptomatic carriers. BMC Infect Dis. 2014;14(453):1471-2334.

13. Hanon E, Hall S, Taylor GP, Saito M, Davis R, Tanaka Y, et al. Abundant tax protein expression in CD4+ T cells infected with human T-cell lymphotropic virus type I (HTLV-I) is prevented by cytotoxic T lymphocytes. Blood. 2000; 95(4):1386-92.

14. Macnamara A, Rowan A, Hilburn S, Kadolsky U, Fujiwara H, Suemori K, et al. HLA class I binding of HBZ determines outcome in HTLV-1 infection. PLoS Pathog. 2010;6(9):e1001117.

15. Vivier E, Raulet DH, Moretta A, Caligiuri MA, Zitvogel L, Lanier LL, et al. Innate or adaptive immunity? The example of natural killer cells. Science. 2011;331(6013):44-9 Epub 2011/01/08.

16. Tattermusch S, Skinner JA, Chaussabel D, Banchereau J, Berry MP, McNab FW, et al. Systems biology approaches reveal a specific interferon-inducible signature in HTLV-1 associated myelopathy. PLoS Pathog. 2012;8(1): e1002480 Epub 2012/02/01.

17. Saito M, Braud VM, Goon P, Hanon E, Taylor GP, Saito A, et al. Low frequency of CD94/NKG2A+ T lymphocytes in patients with HTLV-1associated myelopathy/tropical spastic paraparesis, but not in asymptomatic carriers. Blood. 2003;102(2):577-84.

18. Yu F, Itoyama Y, Fujihara K, Goto I. Natural killer (NK) cells in HTLV-Iassociated myelopathy/tropical spastic paraparesis-decrease in NK cell subset populations and activity in HTLV-I seropositive individuals. J Neuroimmunol. 1991;33(2):121-8.

19. De Castro-Costa CM, Araujo AQ, Barreto MM, Takayanagui OM, Sohler MP, da Silva EL, et al. Proposal for diagnostic criteria of tropical spastic paraparesis/HTLV-I-associated myelopathy (TSP/HAM). AIDS Res Hum Retrovir. 2006;22(10):931-5.

20. Dehee A, Cesaire R, Desire N, Lezin A, Bourdonne O, Bera O, et al. Quantitation of HTLV-I proviral load by a TaqMan real-time PCR assay. J Virol Methods. 2002:102(1-2):37-51

21. Fujihara K, Itoyama Y, Yu F, Kubo C, Goto I. Cellular immune surveillance against HTLV-I infected T lymphocytes in HTLV-I associated myelopathy/ tropical spastic paraparesis (HAM/TSP). J Neurol Sci. 1991;105(1):99-107.

22. Norris PJ, Hirschkorn DF, DeVita DA, Lee TH, Murphy EL. Human T cell leukemia virus type 1 infection drives spontaneous proliferation of natural killer cells. Virulence. 2010;1 (1):19-28.

23. Mascarenhas RE, Brodskyn C, Barbosa G, Clarencio J, Andrade-Filho AS, Figueiroa $\mathrm{F}$, et al. Peripheral blood mononuclear cells from individuals infected with human T-cell lymphotropic virus type 1 have a reduced 
capacity to respond to recall antigens. Clin Vaccine Immunol. 2006;13(5): 547-52 Epub 2006/05/10.

24. Wherry EJ. T cell exhaustion. Nat Immunol. 2011;12(6):492-9 Epub 2011/07/09.

25. Schafer JL, Li H, Evans TI, Estes JD, Reeves RK. Accumulation of cytotoxic CD16+ NK cells in simian immunodeficiency virus-infected lymph nodes associated with in situ differentiation and functional Anergy. J Virol. 2015; 89(13):6887-94 Epub 2015/04/24.

26. Schafer JL, Muller-Trutwin MC, Reeves RK. NK cell exhaustion: bad news for chronic disease? Oncotarget. 2015;6(26):21797-8 Epub 2015/09/24.

27. Garcia-Iglesias T, Del Toro-Arreola A, Albarran-Somoza B, Del Toro-Arreola S, Sanchez-Hernandez PE, Ramirez-Duenas MG, et al. Low NKp30, NKp46 and NKG2D expression and reduced cytotoxic activity on NK cells in cervical cancer and precursor lesions. BMC Cancer. 2009;9:186. Epub 2009/06/18.

28. Bisio F, Bozzano F, Marras F, Di Biagio A, Moretta L, De Maria A. Successfully treated HIV-infected patients have differential expression of NK cell receptors (NKp46 and NKp30) according to AIDS status at presentation. Immunol Lett. 2013;152(1):16-24 Epub 2013/03/30.

29. Holder KA, Stapleton SN, Gallant ME, Russell RS, Grant MD. Hepatitis C virusinfected cells downregulate NKp30 and inhibit ex vivo NK cell functions. J Immunol. 2013;191(6):3308-18. Epub 2013/08/21.

30. Prada N, Antoni G, Commo F, Rusakiewicz S, Semeraro M, Boufassa F, et al. Analysis of NKp30/NCR3 isoforms in untreated HIV-1-infected patients from the ANRS SEROCO cohort. Oncoimmunology. 2013;2(3):e23472 Epub 2013/06/27.

31. Petitdemange C, Wauquier N, Devilliers H, Yssel H, Mombo I, Caron M, et al. Longitudinal analysis of natural killer cells in dengue virus-infected patients in comparison to chikungunya and chikungunya/dengue virus-infected patients. PLoS Negl Trop Dis. 2016;10(3):e0004499 Epub 2016/03/05.

32. Delahaye NF, Rusakiewicz S, Martins I, Menard C, Roux S, Lyonnet L, et al. Alternatively spliced NKp30 isoforms affect the prognosis of gastrointestinal stromal tumors. Nat Med. 2011;17(6):700-7 Epub 2011/05/10.

33. Brandt CS, Baratin M, Yi EC, Kennedy J, Gao Z, Fox B, et al. The B7 family member $\mathrm{B} 7-\mathrm{H6}$ is a tumor cell ligand for the activating natural killer cell receptor NKp30 in humans. J Exp Med. 2009;206(7):1495-503. Epub 2009/06/17.

34. Semeraro M, Rusakiewicz S, Minard-Colin V, Delahaye NF, Enot D, Vely F, et al. Clinical impact of the NKp30/B7-H6 axis in high-risk neuroblastoma patients. Sci TransI Med. 2015;7(283):283ra55 Epub 2015/04/17.

35. Stewart SA, Feuer G, Jewett A, Lee FV, Bonavida B, Chen IS. HTLV-1 gene expression in adult T-cell leukemia cells elicits an NK cell response in vitro and correlates with cell rejection in SCID mice. Virology. 1996;226(2):167-75 Epub 1996/12/15.

36. Carvalho EM, Bacellar O, Porto AF, Braga S, Galvao-Castro B, Neva F. Cytokine profile and immunomodulation in asymptomatic human Tlymphotropic virus type 1-infected blood donors. J Acquir Immune Defic Syndr. 2001;27(1):1-6.

37. Santos SB, Porto AF, Muniz AL, Luna T, Nascimento MC, Guerreiro JB, et al. Modulation of T cell responses in HTLV-1 carriers and in patients with myelopathy associated with HTLV-1. Neuroimmunomodulation. 2006;13(3):145-51.

38. Amorim CF, Carvalho NB, Neto JA, Santos SB, Grassi MFR, Carvalho LP, et al. The role of NK cells in the control of viral infection in HTLV-1 carriers. J Immunol Res. 2019;2019:6574828. Epub 2019/04/05.

39. Demontis MA, Hilburn S, Taylor GP. Human T cell lymphotropic virus type 1 viral load variability and long-term trends in asymptomatic carriers and in patients with human T cell lymphotropic virus type 1-related diseases. AIDS Res Hum Retrovir. 2013;29(2):359-64. Epub 2012/08/17.

40. Nagai M, Usuku K, Matsumoto W, Kodama D, Takenouchi N, Moritoyo T, et al. Analysis of HTLV-I proviral load in 202 HAM/TSP patients and 243 asymptomatic HTLV-I carriers: high proviral load strongly predisposes to HAM/TSP. J Neurovirol. 1998;4(6):586-93.

41. Vakili R, Sabet F, Aahmadi S, Boostani R, Rafatpanah H, Shamsian A, et al. Human T-lymphotropic virus type I (HTLV-I) Proviral load and clinical features in Iranian HAM/TSP patients: comparison of HTLV-I Proviral load in HAM/TSP patients. Iranian J Basic Med Sci. 2013;16(3):268-72 Epub 2014/01/29.

Ready to submit your research? Choose BMC and benefit from:

- fast, convenient online submission

- thorough peer review by experienced researchers in your field

- rapid publication on acceptance

- support for research data, including large and complex data types

- gold Open Access which fosters wider collaboration and increased citations

- maximum visibility for your research: over $100 \mathrm{M}$ website views per year

At BMC, research is always in progress.

Learn more biomedcentral.com/submissions 